\title{
Virtual reality as a non-pharmacologic analgesic for fasciotomy wound infections in acute compartment syndrome: a case report
}

\author{
Ryo Esumi ${ }^{1}$, Ayumu Yokochi ${ }^{2}$, Motomu Shimaoka ${ }^{3}$ and Eiji Kawamoto ${ }^{1,3^{*}}$
}

\begin{abstract}
Background: Fasciotomy is a life-saving procedure to treat acute compartment syndrome, a surgical emergency. As fasciotomy dramatically improves wound pain, it should be performed as soon as possible. Moreover, delays in the use of fasciotomy can increase the rate of wound infections. Once the fasciotomy wound is infected, pain control is achieved via the long-term use of opioids or anti-inflammatory analgesics. However, the administration of high doses of opioids may cause complications, such as respiratory depression, over-sedation, and constipation. Therefore, treatment methods other than narcotic administration should be established to better manage the pain caused by fasciotomy wound infections.

Virtual reality has recently been introduced in analgesic therapy as a replacement, or complement, to conventional pharmacological treatments. Its use has been extensively studied in the pain management of patients with burns. An increasing number of painful conditions are being successfully treated with virtual reality. Here, we report a case of acute compartment syndrome complicated by fasciotomy wound infection.

Case presentation: A 40-year-old Japanese man suffering from acute compartment syndrome of his leg due to a car accident trauma was treated with a fasciotomy to decompress intra-compartmental pressure and restore tissue perfusion, and admitted to an intensive care unit. Unfortunately, as the open fasciotomy wound was complicated by infection, he complained of hyperalgesia and severe pain during wound debridement. He was therefore given acetaminophen and high-dose intravenous patient-controlled analgesic fentanyl ( $35 \mathrm{\mu g} / \mathrm{kg}$ per day) to reduce the pain. Despite these efforts, the pain was poorly controlled and opioid-induced side effects such as respiratory depression were observed. An immersive virtual reality analgesic therapy aimed at distraction and relaxation was used and effectively alleviated the pain. Three sessions of virtual reality analgesic therapy over 2 days produced sustainable analgesic effects, which led to a $25-75 \%$ dose reduction in fentanyl administration and the concomitant alleviation of respiratory depression.

(Continued on next page)
\end{abstract}

\footnotetext{
*Correspondence: a_2.uk@mac.com

'Department of Emergency and Disaster Medicine, Mie University Graduate

School of Medicine, 2-174 Edobashi, Tsu, Mie 514-8507, Japan

${ }^{3}$ Department of Molecular Pathobiology and Cell Adhesion Biology, Mie

University Graduate School of Medicine, 2-174 Edobashi, Tsu, Mie 514-8507,

Japan

Full list of author information is available at the end of the article
}

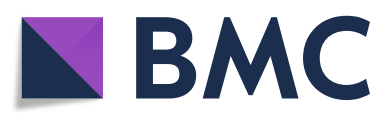

(- The Author(s). 2020 Open Access This article is licensed under a Creative Commons Attribution 4.0 International License, which permits use, sharing, adaptation, distribution and reproduction in any medium or format, as long as you give appropriate credit to the original author(s) and the source, provide a link to the Creative Commons licence, and indicate if changes were made. The images or other third party material in this article are included in the article's Creative Commons licence, unless indicated otherwise in a credit line to the material. If material is not included in the article's Creative Commons licence and your intended use is not permitted by statutory regulation or exceeds the permitted use, you will need to obtain permission directly from the copyright holder. To view a copy of this licence, visit http://creativecommons.org/licenses/by/4.0/. The Creative Commons Public Domain Dedication waiver (http://creativecommons.org/publicdomain/zero/1.0/) applies to the data made available in this article, unless otherwise stated in a credit line to the data. 


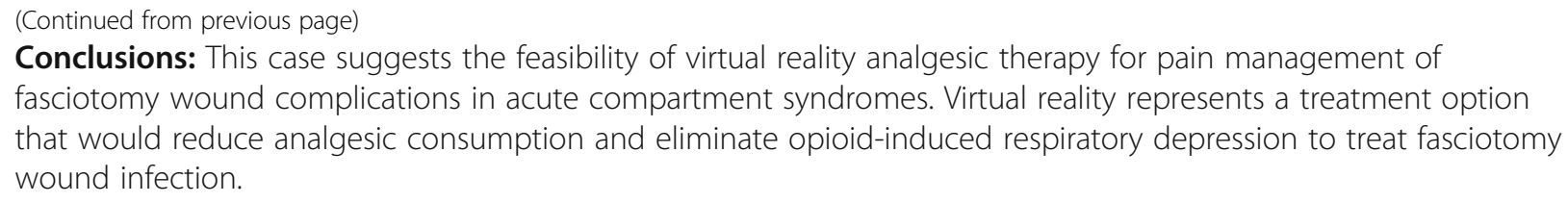

Keywords: Virtual reality, Fasciotomy wound infections, Acute compartment syndrome

\section{Introduction}

Acute compartment syndrome (ACS) is a serious complication of limb trauma, in which the swelling of injured tissues and/or concomitant hematoma causes an increase in intra-compartmental pressure, thereby constraining blood perfusion of the tissues [1]. Ischemia induces neurological symptoms such as numbness and pain. If low or lack of blood perfusion persists, it can ultimately cause tissue necrosis, irreversibly damaging the limbs $[1,2]$.

A prompt execution of fasciotomy is recommended to decompress the intra-compartmental pressure and restore tissue perfusion, once a severe rise in pressure is either confirmed by invasive monitoring or assessed from clinical symptoms [3]. Although early fasciotomy is recommended for those suffering from ACS, this invasive procedure leaves the wound open, thereby endangering patients with potential complications such as wound infections, which have been reported to occur in $10-30 \%$ of cases $[4,5]$.

Severe pain is a hallmark of ACS and strongly suggests the presence of acutely increased intra-compartmental pressure and resulting tissue ischemia, thereby prompting the need for a decompressive fasciotomy [1, 2]. When decompression of the intra-compartmental pressure is achieved by fasciotomy, the intensity of the pain should gradually cease. A short course of opioid treatment is then suitable for pain management in patients with ACS [6]. However, pain can be recurrent and can even worsen when a fasciotomy wound is compounded by infection, thereby complicating the use of opioids for pain management [7-9].

Virtual reality (VR) has recently emerged as a novel analgesic therapy that could replace or complement conventional pharmacological treatments, and has been extensively studied in the pain management of patients with burns. The list of painful conditions successfully treated with VR is growing. Here we add to the list a case of ACS complicated by fasciotomy wound infection. In this case, the patient's pain was difficult to manage with opioids due to intolerable adverse effects such as nausea and respiratory depression.

\section{Case presentation}

A 40-year-old Japanese man, a truck driver, suffered multiple traumas during a road car crash that severely damaged the front part of his truck. While he was trapped in the driver's seat, his lower-right limb was strongly pinched against the dashboard for 8 hours until he was saved by a rescue team. He was then transferred to an intensive care unit (ICU) at Mie University Hospital, a tertiary academic medical care center.

He was fully alert and complained of severe pain, along with numbness and weakness, in his right limb. A fullbody computed tomography scan revealed multiple rib and lumbar compression fractures. His right lower leg had no fractures; however, the muscles in his lower leg were significantly swollen after the prolonged compression. After placing intramuscular catheters to monitor the intra-compartment pressures of his lower limb, the trauma team found that the pressures in the anterior, posterior, medial, and lateral side compartments had risen to $\sim 50 \mathrm{mmHg}$. Based on these findings, he was diagnosed as having ACS, and quickly underwent a fasciotomy of his right lower limb. The fasciotomy wounds were left open (Fig. 1 top panels), and were cleaned daily and wrapped in a dressing containing an antibiotic ointment.

After the fasciotomy, the neurological deficits of his right limb were gradually restored and the pain intensity was reduced, made manageable by opioid treatment for at least for 4 days (Fig. 2).

He exhibited rhabdomyolysis with increased levels of serum creatine phosphokinase (CPK) and acute renal failure, possibly due to the ischemia reperfusion injury associated with ACS (Fig. 3). His CPK level progressively decreased and returned to normal levels on day 10, indicating resolution of the rhabdomyolysis. Acute renal failure temporarily required hemodialysis for 5 days, and he subsequently recovered.

The pain at the fasciotomy wounds on his right leg was well managed for 4 days (days 1 to 4 ), as shown by the score of 5 points on the Numeric Rating Scale (NRS) for pain $(0-10)$ [10], via intravenous patient-controlled analgesia (IV-PCA) fentanyl at a dose of $\sim 12 \mu \mathrm{g} / \mathrm{kg}$ per day (Fig. 2). On day 5, owing to the onset of nausea, IVPCA fentanyl was discontinued and replaced with a drip infusion of acetaminophen. However, as acetaminophen could not sufficiently control the pain, IV-PCA fentanyl was resumed along with antiemetic agents on day 6 . On day 8 , as our patient's pain at the wounds intensified, we observed the appearance of defective granulation and 


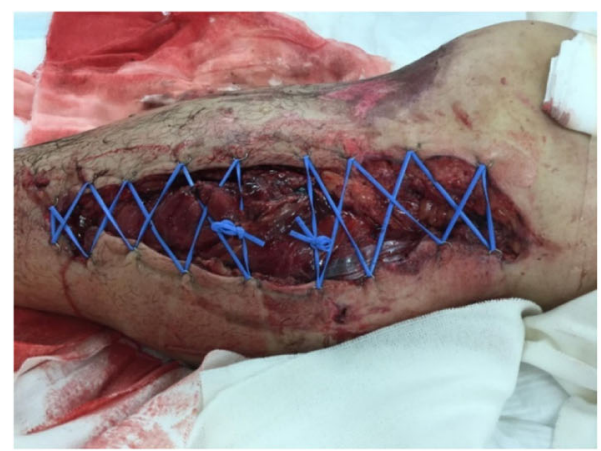

(a)

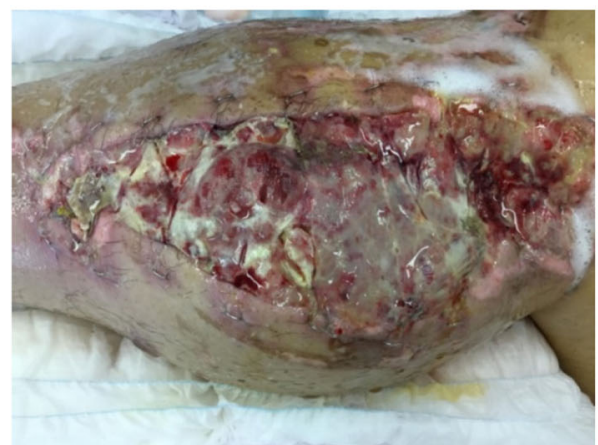

(c)

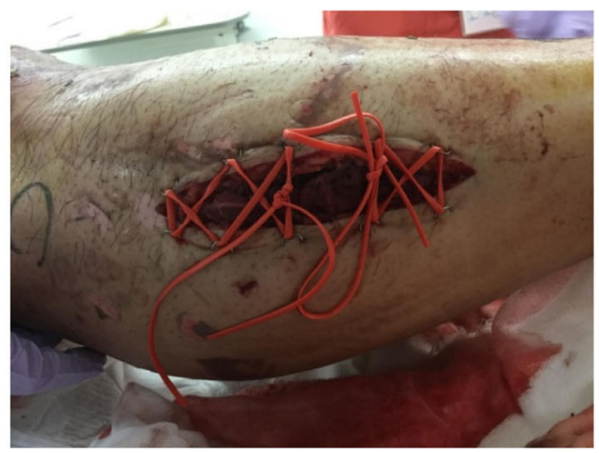

(b)

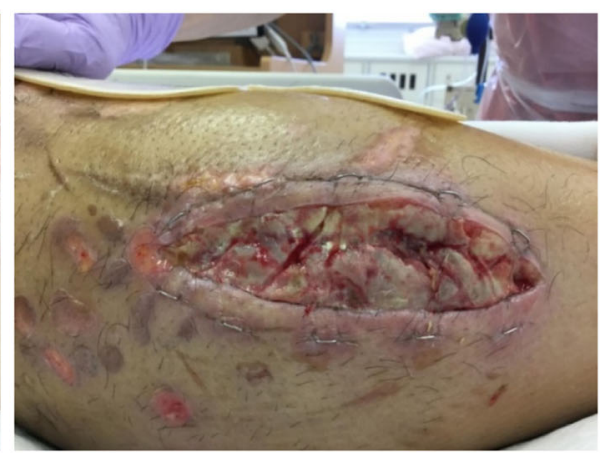

(d)

Fig. 1 Clinical images of right foot acute compartment syndrome in a 40-year-old man injured in a road car accident. (Top) Images taken immediately after the fasciotomy on day 1; (bottom) images taken on day 8, showing wound infections. (a) and (c) indicate the inside of the lower leg. (b) and (d) indicate the outside of the lower leg

necrotic tissue at the site of the fasciotomy despite adequate infection prevention. In addition, the wounds exuded a foul odor and were strongly suggestive of infection (Fig. 1 bottom panels). To control the wound infections, debridement of the infected necrotic tissues was performed.

Although the wound infections appeared to be under control with antibiotics and debridement, our patient continued to complain of severe pain both during and between procedures, as shown by the NRS of $6-10$ points. The pain experienced was self-described as if being stabbed with a pin or a needle or, alternately, a numbness resulting in a dull sensation. The pain began abruptly, irrespective of body movement, and lasted for approximately 1 hour. A dose of IV-PCA fentanyl to manage the pain was progressively increased up to $35 \mu \mathrm{g} / \mathrm{kg}$ per day from day 10 to 13 . He also presented hyperalgesia of his right limb beginning at day 10. In addition, nausea and poor appetite worsened as a side effect of high-dose fentanyl, and he experienced loud snoring and excessive daytime sleepiness due to opioidinduced respiratory depression; as such, he was administered oxygen to prevent hypoxia. We consulted with an in-hospital pain control team about a pain management strategy to replace/complement opioid administration.
They confirmed the presence of opioid-refractory severe pain and hyperalgesic states, and proposed the use of VR analgesia.

On day 14, he was provided with an immersive VR using the Samsung Gear Oculus headset fitted with a Samsung Galaxy S7 phone loaded with the AppliedVR (AVR) healthcare platform (AppliedVR Inc., Los Angeles, CA 90067, USA), which delivers various VR analgesia program modules. Of 20+ VR programs designed to distract and/or relax, the program "Dream Beach" was selected according to our patient's preference for the sea. The VR program simulates the experience of being at the beach beside a calm sea on a sunny day. Each session lasted for $30 \mathrm{mi}-$ nutes and three sessions were administered over 2 days. The VR analgesic proved effective, as his pain rating fell dramatically from 10 to 6 points. On day 15 , the second day of VR administration, its analgesic effects proved so successful that bolus infusions of IV-PCA fentanyl were no longer required. On day 16 , the pain rating scale remained 2 points under a baseline IV-PCA infusion of $8.8 \mu \mathrm{g} / \mathrm{kg}$ per day fentanyl, and as the wound pain became manageable, he was transferred from the ICU to a general surgery ward at a secondary care hospital. At day 28 , after the fasciotomy, he was free of opioids and the wounds were closed using split-thickness skin grafting. 


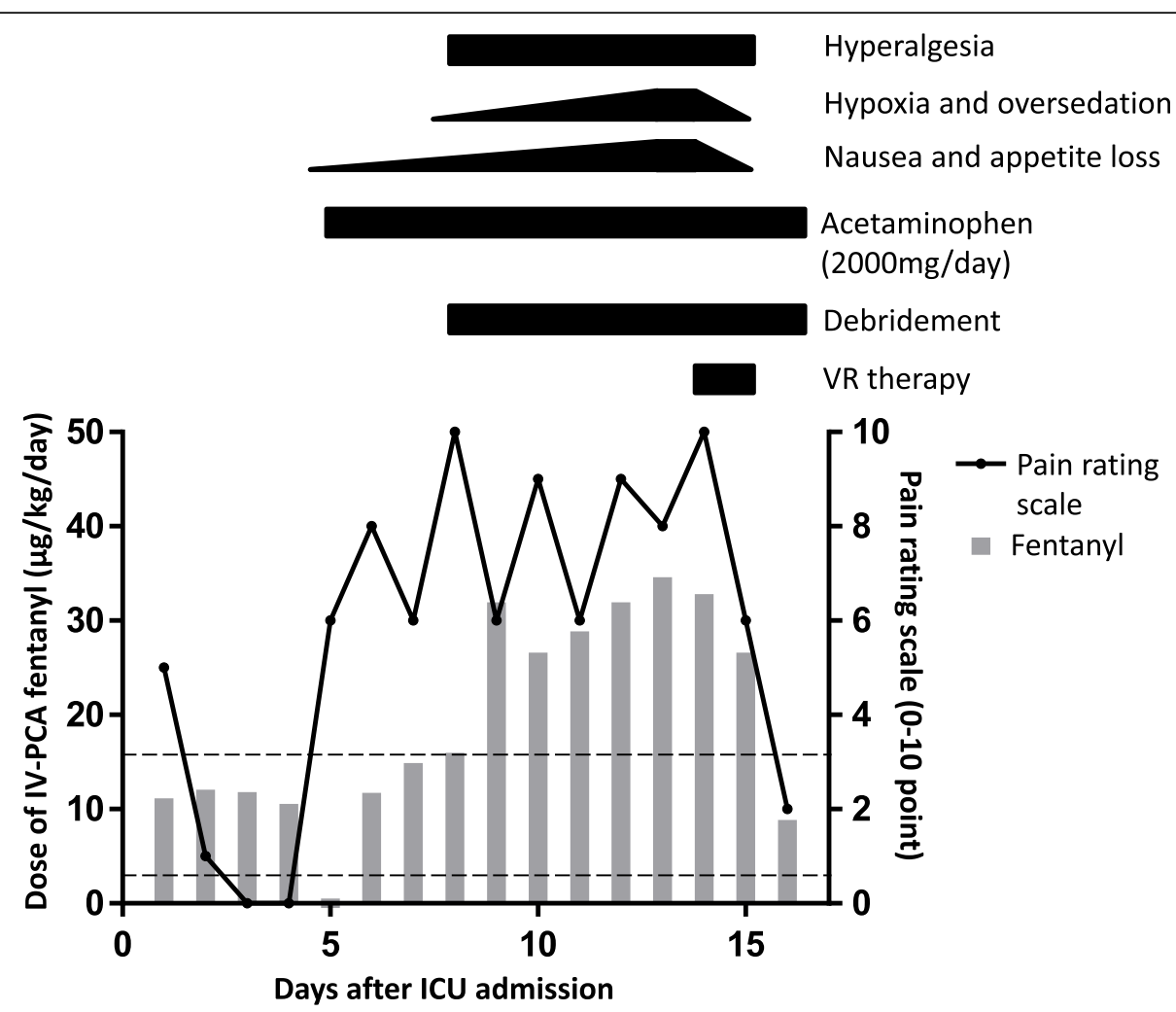

Fig. 2 Clinical course of intravenous patient-controlled analgesia fentanyl using a 0-10 pain rating scale. On days 14 and 15, the patient was administered an immersive virtual reality. Debridement of infected necrotic tissues was performed beginning on day 8 . The dotted line represents the appropriate continuous intravenous infusion of fentanyl $(2.88-16.08 \mu \mathrm{g} / \mathrm{kg}$ per day). The time courses for the major clinical events and approximate intensities of the opioid-induced adverse effects are shown. ICU intensive care unit, IV-PCA intravenous patient-controlled analgesia, $V R$ virtual reality

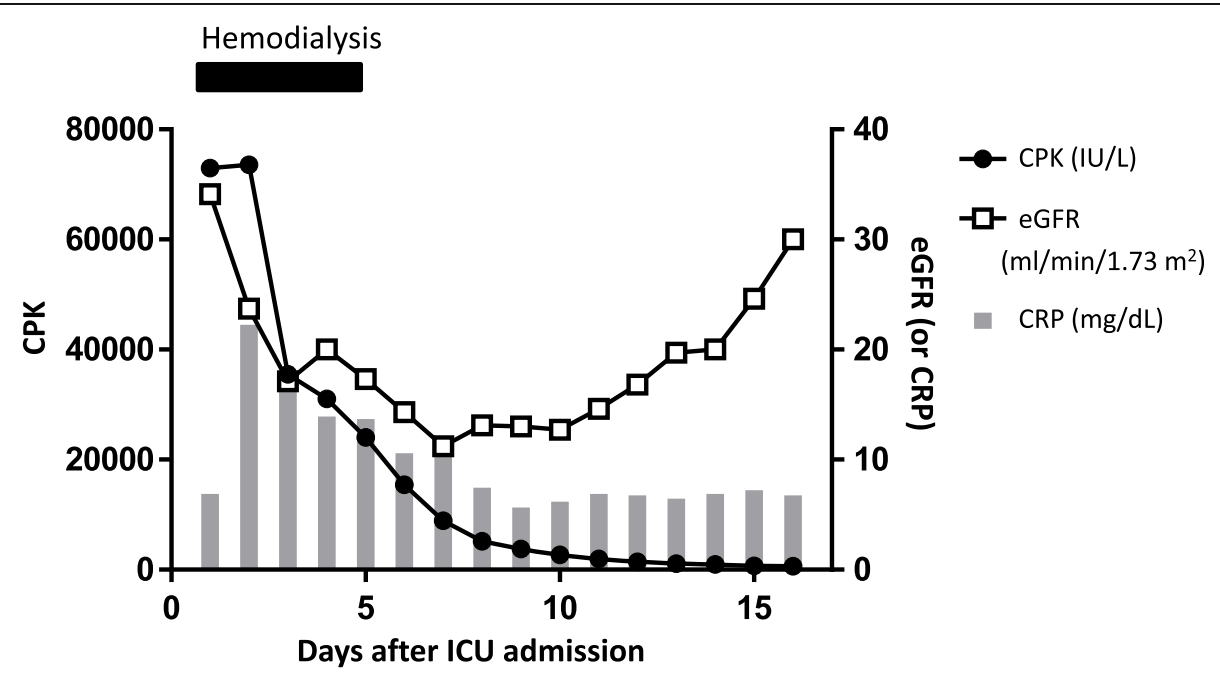

Fig. 3 Time course of rhabdomyolysis (creatine phosphokinase), acute renal failure (estimated glomerular filtration rate), and inflammation (Creactive protein). Hemodialysis was performed only for the first 5 days. Creatine phosphokinase values are indicated on the left axis, the estimated glomerular filtration rate values are indicated on the right axis, and C-reactive protein values are indicated on the right axis. CPK creatine phosphokinase, CRP C-reactive protein, eGFR estimated glomerular filtration rate, ICU intensive care unit 


\section{Discussion and conclusions}

In this case report, we present a successful application of an immersive VR experience to alleviate severe pain from the open fasciotomy wounds of a patient with ACS who had been treated with a high-dose (that is, $35 \mu \mathrm{g} / \mathrm{kg}$ per day fentanyl) IV-PCA opioid, which became intolerable due to adverse effects such as nausea and respiratory depression. The analgesic effects brought about by this immersive VR experience to our patient made it possible to reduce the doses of IV-PCA fentanyl by 25 75\%, which alleviated the opioid-induced respiratory depression. This case study not only confirms previous reports showing the effectiveness of VR to alleviate pain during wound care and physical therapy in patients with burns $[11,12]$, but also illustrates the feasibility of using a VR analgesic to manage pain in a patient with ACS.

In patients with $\mathrm{ACS}$, the pain during the early phase - that is, within several days after fasciotomy - may stem from physical tissue damage and inflammation, as well as from ischemia and ischemia-reperfusion that can damage neuronal and non-neuronal cells $[1,6]$. Generally speaking, pain in the early phase gradually decreases, as inflammation resolves while the wounds heals. Such pain is usually manageable in the early phase with opioids, as occurred in our case [6]. In contrast, pain in the late phase - that is, several days after the fasciotomy may indicate the presence of complications associated with ACS and fasciotomy, such as wound infections and neuropathic pain $[2,4]$. Pain in the late phase is often not well managed with opioids, as was observed in this case. This is partly due to the fact that prolonged use of opioids is accompanied by several adverse effects, from nausea, itching, and constipation to respiratory depression and the development of tolerance and dependency [13]. Of note, opioids have been shown to exhibit a wide range of immune-suppressive effects [14], thereby potentially worsening wound infections [15]. Hyperalgesia also occurred in our case. Hyperalgesia can be divided into three types: primary, secondary, and opioid-induced. Primary hyperalgesia is caused by the exacerbation of pain due to tissue damage. Secondary hyperalgesia involves the spreading to undamaged tissue. In general, pain spreads to the areas surrounding the damaged tissue. Opioid-induced hyperalgesia is thought to be induced by the administration of opioids such as morphine and fentanyl to relieve pain [16]. However, the narcotic side effects can be severe enough to warrant discontinuation of opioid treatment. In the current case, as primary or opioid-induced hyperalgesia may have occurred, it was necessary to reduce the dose of fentanyl as quickly as possible. Thus, it is of great clinical significance that a VR analgesic proved effective in alleviating the pain in the late phase of a patient with ACS treated with fasciotomy, thereby reducing the need for opioids [12].
Continuous infusion of fentanyl at $2.88-16.08 \mu \mathrm{g} / \mathrm{kg}$ per day for several days has often been safely used without any serious side effects such as respiratory depression $[17,18]$. The appearance of serious adverse effects such as respiratory depression, which can require intubation, would hamper the continuous use of high-dose fentanyl [19], as was the case in this report. Thus, a pain management approach that would replace/complement opioids, thereby mitigating the risk of opioid-induced respiratory depression, would be extremely useful in ICUs and other clinical settings. In fact, opioid-induced respiratory depression represents the major morbidity associated with opioid abuse [20]. Considering the adverse effects of opioids and the serious negative social impact of widespread opioid addiction that originates from the misuse of prescription drugs [21], alternative means of pain control that can reduce opioid usage are of great clinical importance. VR is a promising nonpharmacological means to replace and/or complement opioids [12]. It has been shown in healthy individuals that the thermal stimulation of VR confers additive analgesic effects to opioid treatment in alleviating pain [22]. Consistent with these findings, our own case of ACS showed that pain relieved by VR resulted in reduced opioid requirements, which alleviated our patient's opioidinduced respiratory depression. Further investigations would be needed to test how well VR can replace/complement opioid analgesics in acute and chronic pain conditions in various diseases.

The major mechanism by which the VR program described in our case reduced pain was distraction, which is designed to dilute a patient's attention to pain, supplanted by an immersive VR environment, which modulates a patient's pain perception [12]. Relaxation, another mechanism closely related to distraction, was also employed in our VR analgesic regimen. As pain perception can be influenced by a patient's affect (a psychological term describing the experience of positive emotion), shifting the distressing circumstances of being in a wounded state in a hospital room toward the much more enjoyable circumstances of a pleasant VR environment gives rise to a positive effect, which alleviates pain. To optimize the effects of distraction and relaxation, proper selection of the VR content is critically important. In fact, although we prescreened $20+$ available VR programs based on our patient's preference for the sea, the "Dream Beach" program proved effective, while the "Sea Hospital" program, which simulates the experience of being at a pool with seals, was not effective.

Although not applicable to the present case, focusshifting and skill-building represent two additional advanced mechanisms of VR analgesia [12]. As is often observed in gaming-type VR programs such as "Bear Blast", which involves a shooting game to target bears 
with cannon balls, focus-shifting potently shifts one's attention to VR objects, and requires the user's focused interaction with a VR environment. It has been shown in patients with burns that VR analgesics based on focus-shifting mechanisms are more effective at alleviating pain than that of mere passive distraction [23]. Skill-building aims to foster a patient's capacity to achieve a certain mental state, such as mindfulness mediation, in order to control their mental and physical responses to painful conditions [24, 25]. As skillbuilding would require more active engagement than simple passive distraction [12], this might prove difficult for some patients in ICU. Skill-building VR is expected to be effective for the management of chronic pain [12].

How long the analgesic effects of VR can last represents an important and unresolved question. It has been shown that the preoperative administration of immersive VR experiences made pediatric patients more resilient to postoperative pain [26]. It is possible that VR analgesia, under certain settings, may give rise to sustainable modulation of pain perception. In our case, our patient felt significantly less pain not only during, but also sometime after administration of the VR analgesic, thus suggesting that the effects could last for hours or days. A possible explanation for the long-lasting analgesic effects of VR in our case might be that a VR-induced positive shift of our patient's affect helped modulate pain perception in a lasting manner, continuing even after the VR session had ended [12].

A potential limitation of VR analgesics is the cost of introducing such a platform (including software and hardware) to clinics. Although the initial expenses might be high, one recent economic analysis using computer modeling has estimated that, overall, VR analgesic therapy would be cost saving whenever it reduced the length of hospitalization [27]. Real-world economic analyses are needed to carefully assess the economic benefits of VR analgesic therapies. In addition, potential adverse effects, if any, might limit the utility of VR analgesia in clinics. Several clinical studies have occasionally, though quite infrequently, reported minor incidences such as nausea, thereby supporting the overall safety profile of VR's clinical applications [11]. As is sometime seen in recreational VR users, motion sickness, which can induce nausea, is a major factor potentially limiting the utility of VR analgesia [28]. Investigations into human and machine factors affecting susceptibility to nausea, as well as the development of novel technologies mitigating such side effects are currently underway.

\section{Abbreviations}

VR: Virtual reality; IV-PCA: Intravenous patient-controlled analgesia; NRS: Numeric Rating Scale; ACS : Acute compartment syndrome; ICU: Intensive care unit; CPK: Creatine phosphokinase
Acknowledgements

We would like to acknowledge the patient for allowing his case to be published.

\section{Authors' contributions}

$R E$, EK, and MS designed the study, and wrote the initial draft of the manuscript. EK and MS contributed to analysis and interpretation of data, and assisted in the preparation of the manuscript. AY has contributed to data collection and interpretation, and critically reviewed the manuscript. All authors approved the final version of the manuscript.

\section{Funding}

This work was supported by ISPS KAKENHI (Grants-in-Aid for Scientific Research) grant numbers 18 K16536, 2019; grant numbers 18 K08916, 2019; and grant numbers 17 K11049, 2019.

\section{Availability of data and materials \\ Not applicable.}

Ethics approval and consent to participate

Not applicable for case report.

\section{Consent for publication}

Written informed consent was obtained from the patient for publication of this manuscript and accompanying images. A copy of the written consent is available for review by the Editor-in-Chief of this journal.

\section{Competing interests}

The authors declare that they have no competing interests.

\section{Author details}

'Department of Emergency and Disaster Medicine, Mie University Graduate School of Medicine, 2-174 Edobashi, Tsu, Mie 514-8507, Japan. ${ }^{2}$ Department of Anesthesiology and Critical Care Medicine, Mie University Graduate School of Medicine, 2-174 Edobashi, Tsu, Mie 514-8507, Japan. ${ }^{3}$ Department of Molecular Pathobiology and Cell Adhesion Biology, Mie University Graduate School of Medicine, 2-174 Edobashi, Tsu, Mie 514-8507, Japan.

Received: 4 December 2019 Accepted: 16 March 2020

Published online: 14 April 2020

\section{References}

1. Schmidt AH. Acute compartment syndrome. Injury. 2017;48(Suppl 1):S22-5.

2. Sands AK, Rammelt $S$, Manoli A 2nd. Foot compartment syndrome-a clinical review. Fuß \& Sprunggelenk. 2015;13:11-21.

3. Walters TJ, Kottke MA, Hargens AR, Ryan KL. Noninvasive diagnostics for extremity compartment syndrome following traumatic injury: A state-of-theart review. J Trauma Acute Care Surg. 2019;87:S59-66.

4. Dover M, Memon AR, Marafi H, Kelly G, Quinlan JF. Factors associated with persistent sequelae after fasciotomy for acute compartment syndrome. J Orthop Surg (Hong Kong). 2012;20:312-5.

5. Hake ME, Etscheidt J, Chadayammuri VP, Kirsch JM, Mauffrey C. Age and dressing type as independent predictors of post-operative infection in patients with acute compartment syndrome of the lower leg. Int Orthop. 2017:41:2591-6.

6. Mar GJ, Barrington MJ, McGuirk BR. Acute compartment syndrome of the lower limb and the effect of postoperative analgesia on diagnosis. Br J Anaesth. 2009;102:3-11.

7. Lollo L, Grabinsky A. Clinical and functional outcomes of acute lower extremity compartment syndrome at a Major Trauma Hospital. Int J Crit IIIn Inj Sci. 2016;6:133-42.

8. Fitzgerald AM, Gaston P, Wilson Y, Quaba A, McQueen MM. Long-term sequelae of fasciotomy wounds. Br J Plast Surg. 2000;53:690-3.

9. Brown A. Strategies to reduce or eliminate wound pain. Nurs Times. 2014; 110:12-5.

10. Chanques G, Viel E, Constantin JM, Jung B, de Lattre S, Carr J, Cisse M, Lefrant JY, Jaber $S$. The measurement of pain in intensive care unit: comparison of 5 self-report intensity scales. Pain. 2010;151:711-21.

11. Indovina P, Barone D, Gallo L, Chirico A, De Pietro G, Giordano A. Virtual Reality as a Distraction Intervention to Relieve Pain and Distress During 
Medical Procedures: A Comprehensive Literature Review. Clin J Pain. 2018; 34:858-77.

12. Ahmadpour N, Randall H, Choksi H, Gao A, Vaughan C, Poronnik P. Virtual Reality interventions for acute and chronic pain management. Int J Biochem Cell Biol. 2019;114:105568.

13. Chou R, Fanciullo GJ, Fine PG, Adler JA, Ballantyne JC, Davies P, Donovan MI, Fishbain DA, Foley KM, Fudin J, et al. Clinical guidelines for the use of chronic opioid therapy in chronic noncancer pain. J Pain. 2009;10:113-30.

14. Roy S, Wang J, Kelschenbach J, Koodie L, Martin J. Modulation of immune function by morphine: implications for susceptibility to infection. J Neurolmmune Pharmacol. 2006;1:77-89.

15. Schwacha MG, McGwin G, Hutchinson CB, Cross JM, Maclennan PA, Rue LW. The contribution of opiate analgesics to the development of infectious complications in burn patients. Am J Surg. 2006;192:82-6.

16. Lee M, Silverman SM, Hansen H, Patel VB, Manchikanti L. A comprehensive review of opioid-induced hyperalgesia. Pain Physician. 2011;14:145-61.

17. Shin S, Min KT, Shin YS, Joo HM, Yoo YC. Finding the 'ideal' regimen for fentanyl-based intravenous patient-controlled analgesia: how to give and what to mix? Yonsei Med J. 2014;55:800-6.

18. Song JW, Park EY, Lee JG, Park YS, Kang BC, Shim YH. The effect of combining dexamethasone with ondansetron for nausea and vomiting associated with fentanyl-based intravenous patient-controlled analgesia. Anaesthesia. 2011;66:263-7.

19. Pattinson KT. Opioids and the control of respiration. Br J Anaesth. 2008;100: $747-58$.

20. Dahan A, Overdyk F, Smith T, Aarts L, Niesters M. Pharmacovigilance: a review of opioid-induced respiratory depression in chronic pain patients. Pain Physician. 2013;16:E85-94.

21. Volkow ND, McLellan AT. Opioid Abuse in Chronic Pain--Misconceptions and Mitigation Strategies. N Engl J Med. 2016;374:1253-63.

22. Hoffman HG, Richards TL, Van Oostrom T, Coda BA, Jensen MP, Blough DK, Sharar SR. The analgesic effects of opioids and immersive virtual reality distraction: evidence from subjective and functional brain imaging assessments. Anesth Analg. 2007;105:1776-83. table of contents.

23. Jeffs D, Dorman D, Brown S, Files A, Graves T, Kirk E, Meredith-Neve S, Sanders J, White B, Swearingen CJ. Effect of virtual reality on adolescent pain during burn wound care. J Burn Care Res. 2014;35:395-408.

24. Hadley W, Houck C, Brown LK, Spitalnick JS, Ferrer M, Barker D. Moving Beyond Role-Play: Evaluating the Use of Virtual Reality to Teach Emotion Regulation for the Prevention of Adolescent Risk Behavior Within a Randomized Pilot Trial. J Pediatr Psychol. 2019;44:425-35.

25. Nararro-Haro MV, Hoffman HG, Garcia-Palacios A, Sampaio M, Alhalabi W, Hall K, Linehan M. The Use of Virtual Reality to Facilitate Mindfulness Skills Training in Dialectical Behavioral Therapy for Borderline Personality Disorder: A Case Study. Front Psychol. 2016;7:1573.

26. Eijlers R, Dierckx B, Staals LM, Berghmans JM, van der Schroeff MP, Strabbing EM, Wijnen RMH, Hillegers MHJ, Legerstee JS, Utens EMWJ. Virtual reality exposure before elective day care surgery to reduce anxiety and pain in children: A randomised controlled trial. Eur J Anaesthesiol. 2019;36:728-37.

27. Delshad SD, Almario CV, Fuller G, Luong D, Spiegel BMR. Economic analysis of implementing virtual reality therapy for pain among hospitalized patients. NPJ Digit Med. 2018;1:22.

28. Fernandes AS, Feiner SK. Combating VR sickness through subtle dynamic field-of-view modification. In: IEEE Symposium on 3D User Interfaces (3DUI); 2016. p. 201-10.

\section{Publisher's Note}

Springer Nature remains neutral with regard to jurisdictional claims in published maps and institutional affiliations.

Ready to submit your research? Choose BMC and benefit from:

- fast, convenient online submission

- thorough peer review by experienced researchers in your field

- rapid publication on acceptance

- support for research data, including large and complex data types

- gold Open Access which fosters wider collaboration and increased citations

- maximum visibility for your research: over $100 \mathrm{M}$ website views per year

At $\mathrm{BMC}$, research is always in progress.

Learn more biomedcentral.com/submissions 